\title{
MULTI-PROFESSIONAL WORKING AND LEARNING?: TEAMS OR TERRITORIALISM IN THE E-LEARNING AGE
}

\author{
Sue Roberts \\ Head of Learning Services, \\ Edge Hill College of Higher Education, \\ Ormskirk, Lancashire, L39 4QP UK \\ robertss@edgehill.ac.uk
}

\begin{abstract}
This paper focuses upon the changing roles of library and information professionals in educational settings in the context of e-learning. The focus is on UK higher education but the issues explored have resonance with other contexts. The paper particularly highlights the impact of the rise of learning technologists as a professional group over the last decade and their relationship with the role of the information professional. Several studies of the roles of learning technologist and subject librarian/information specialist highlight similarities and blurred boundaries as a result of the growth in elearning. Evidence suggests that this 'convergence of roles' can either lead to the development of multi-professional teams and multi-professional learning, or to conflict and disputed territories. This paper explores developments in the two roles, reviewing the literature and providing a case study; it then proceeds to suggest models for multi-professional working and learning. Whilst partnership with academic staff is not the subject of this paper, it must be stressed that this is key to e-learning developments.
\end{abstract}

\section{Introduction}

E-learning has rapidly become an integral part of UK higher education (HE), though not, as originally anticipated, as a replacement for face-to-face teaching. E-learning is defined here as "the use of digital technologies and media to deliver, support and enhance teaching, learning, assessment and evaluation"1 and as such can involve a range of technologies and tools. 'Blended learning' as a term has also gained credence, providing a spectrum of methods and approaches that range from learning and teaching occurring purely online, to e-learning elements complementing face-to-face learning. Within this context library and information services and their staff have taken a variety of roles. Whilst involvement is far from consistent, either within or across institutions, library and information services' staff are undoubtedly becoming increasingly active in e-learning and this is impacting upon their roles, professional identity and relationships with other groups of staff. This is particularly pertinent in relation to the 'new professional' group of learning technologists who have emerged as a recognizable body over the last five years. The changes in the two roles are explored here in the context of collaboration. This paper proposes that for effective e-learning development to take place a multi-professional team approach is crucial. Such a team approach can be fostered by the development of mutual understanding of roles and by collaborative learning. The case study presented here explores a model of such working and learning in a UK higher education institution (HEI).

\section{The e-learning imperative}

E-learning is very clearly on the political agenda for universities in the UK, indicated by the draft e-learning strategies of both the Department for Education and Skills (DfES) and 
the Higher Education Funding Council for England (HEFCE). But why is e-learning viewed by government as so key to the future of higher education and to lifelong learning?

[it] is important because people are finding that e-learning can make a significant difference: to how quickly they master a skill; how easy it is to study; and, of course, how much they enjoy learning. It is important because it can contribute to all the Government's objectives for education - to raising standards; improving quality; removing barriers to learning and participation in learning; preparing for employment; upskilling in the workplace; and ultimately, ensuring that every learner achieves their full potential. ${ }^{2}$

Such national emphasis is also reflected in local developments with many HEIs developing elearning strategies, adopting an institutional Virtual Learning Environment (VLE), and establishing E-Learning Development Units or teams with the associated growth of learning technologist roles. The commitment to e-learning within the UK HE sector is evidenced in two reports commissioned by UCISA (Universities and Colleges Information Systems Association); the first documents the rise of the use of VLEs in 2000 and 2001, whilst the second continuation report in 2003 observes that "The overall picture is one of evolutionary consolidation. Centralisation is increasing of matters considered strategic". ${ }^{3}$ This image of elearning as a force for change is reinforced by Jenkins and Hanson, as "[it] will require change at all levels of an institution and for all categories of staff". 4

Consequently, it is clear that technological developments have impacted considerably upon the HE learning environment. However, it would be overly simplistic to take a purely technologically deterministic view of change. The e-learning imperative must be couched in the context of the rising profile of learning and teaching itself generally. Political acknowledgement of this is evident in the Dearing Report's ${ }^{5}$ desire that the effectiveness of teaching and learning should be advanced. In addition, this is reflected in such imperatives as the need for HEIs to develop their own Learning and Teaching Strategies, introduced by HEFCE in the 1990s. A key indicator and driver of this trend has been the introduction of the Institute for Learning and Teaching in Higher Education (ILTHE) to set and raise standards (this has since been merged into the HE Academy, established in 2004). With a focus on recognising and rewarding excellence, HEFCE has also introduced the concept of Centres for Excellence in Teaching and Learning (CETL). The CETL initiative has two main aims. Firstly, to reward excellent teaching practice, and secondly, to further invest in that practice so that the funding delivers substantial benefits to students, teachers and institutions.

\section{E-learning and convergence models}

This emphasis on learning and teaching, and on the opportunities that new learning environments aided by technology bring, is having a significant impact on professional roles across HE and on the ways in which groups work together. This can usefully be explored within the concept of models of convergence. Convergence emerged as a central and influential notion in the UK library and information literature following the publication of the Follett and Fielden Reports. ${ }^{6,7}$ Convergence can be defined relatively narrowly, as;

"the bringing together of the library and computing services, possibly with other

separate support services, under the management of an executive director". 8

Or, more loosely, as the bringing together, either organisationally or operationally, of different elements of academic support services. Fielden cautions, "It would be a mistake to focus just on computing and libraries coming together”, and points to different convergence models between library and information services and other services with responsibilities for IT, staff development, media, reprographics, student welfare and educational development. ${ }^{7}$ This explicit warning not to focus too exclusively on certain models, with the prediction of 
mergers with "new technology services" and student services, is particularly pertinent in the more recent e-learning environment.

There is another model of convergence that moves away from organisational and formal models, stemming from the notion of 'academic convergence' articulated by Fielden. ${ }^{7}$ This notion of role convergence has been further developed in the context of learner support and learning technologies with the concept of 'learner-centric services' placing the learner at the core with a range of staff converging on them. ${ }^{9}$ Authors such as Currier ${ }^{10}$ and Core ${ }^{11}$ have also pointed to the need for new convergences between library and educational development services as well as computing in the light of developments in e-learning. Core recommends that support services in general need to develop models for support that "cross organisationally discrete services". ${ }^{11}$ It can be argued that this second model of convergence, with its aim to maximise the focus on the learner (and not technology or systems) has been more significant in "making a real change to the student (and academic staff) experience of a learning environment”. ${ }^{12}$

A clear theme in the literature is that support for e-learning is needed from a range of (often dispersed) services and professional roles - IT, Library, Educational development, new E-learning development units - and that it is consequently imperative that "cognate areas are linked or work closely together to help encourage synergy in working practices" ${ }^{4}$ It is the synergy and collaboration between two specific groups to which this paper now turns.

\section{Impact of e-learning on library and information services}

Library and information services are increasingly involved in e-learning at various levels, for example in the discovery and embedding of electronic resources, the design of materials, e-support and e-tutoring. Allen suggests that "E-learning is becoming an increasingly important approach to user education, information literacy and also staff development", ${ }^{13}$ a view that is evidenced the growing case studies of library and information services involvement in e-learning projects, particularly in relation to electronic resources and supporting learners online. ${ }^{9}$

As highlighted above, new organisational models are also providing new opportunities. Whilst no two HEIs will have exactly the same models of convergence, there are examples of broadly based 'Information Services' or 'Learning Services' which have incorporated e-learning development teams. Where this isn't the case, library and information services' staff are increasingly working in collaboration with staff from other services such as Educational Development Units to provide support, resources and frameworks for e-learning developments. Many authors and practitioners see e-learning as a great opportunity to develop new partnerships, to inform strategic direction, to influence, and to reposition library and information services. ${ }^{15}$ There is, however, the perceived threat that library and information services can be and will be bypassed in e-learning developments, for in the e-learning environment "many of the established mechanisms that were once in place to support teaching and learning have been compromised, or overlooked...In many instances this has included the library". ${ }^{15}$

\section{The role of the library and information professional}

There is a focus in the library and information literature upon the changing role of the subject librarian or information specialist. This group is depicted unanimously as being at the forefront of change and role development (see for example Pinfield ${ }^{16}$ and Moore ${ }^{17}$ for a UK perspective). This emphasis is also reflected by US and Australian authors such as Stoffle ${ }^{18}$ and Riggs. ${ }^{19}$ 
The role of subject librarian is not itself unambiguous with several authors seeing the changes in job titles - 'Academic liaison adviser,' 'Learning Adviser', 'Subject Liaison' etc as indicative of role developments and complexity with an increased focus on the learner and learning and teaching. This paper uses the different terms interchangeably, intending to refer to the widest range of roles that are directly involved in learner support. Changes in these roles have been well documented in the literature over the past decade and can be categorised broadly as:

- more proactive approach to academic liaison,

- $\quad$ role in delivery of learning and teaching particularly but not exclusively in relation to information literacy development,

- $\quad$ technology-related change for example skills required for Networked Learner Support, impact of e-learning,

- $\quad$ move towards more strategic alliances and partnerships via both formal and informal convergence.

The key messages emerging from the literature are that the role of the academic librarian is growing closer to that of the academic and is also closely related to the relatively new role of the learning technologist. This is particularly true in the context of networked learning support where information specialists have developed new approaches to supporting learners in the electronic environment, for example, using online tutorials, embedding eresources into VLEs.

\section{The rise of the 'new professionals'}

In the context of developments in learning and teaching and technology, the UK HE sector has seen the emergence of a new group of professionals -learning technologists. Definitions of learning technology and learning technologists are a useful starting point. The Association of Learning Technology (ALT) understands learning technology as "the systematic application of a body of knowledge to the design, implementation and evaluation of teaching and learning". Learning technologists apply "learning technology in practice and/or do research into learning technology". ${ }^{20}$ Interestingly, ALT emphasise that a wide range of individuals have learning technology as a core part of their role - across a range of sectors, not just HE - and that "you do not have to be called or to call yourself a learning technologist to be one!” This latter point highlights the complexity and potential blurring of roles as learning technology can form an element of many other roles. This is also reinforced in Beetham's research into the career development of learning technologists. ${ }^{21}$ She found three groups of staff in the HE sector who were involved in learning technology work:

1. New specialists, including educational or technical developers, researchers and managers. New specialists tend to be multiskilled and peripatetic, but with learning technologies at the core of their professional identity.

2. Academics and established professions (such as librarians) who have incorporated an interest in or a formal responsibility for learning technologies into their existing professional identities.

3. Learning support professionals that support access to and effective use of learning technologies. Unlike new specialists they do not regard learning technologies as the defining focus of their professional identity but as the context in which they are working.

The rise of the learning technologist as a recognised profession has been supported by the work of a range of writers. They have argued that this group do now have a sense of their own professional identity; they are developing their own community of practice, associations, networks and moving towards a professional accreditation scheme. As Oliver states, ${ }^{22}$ there is 
no definitive account of the development of the learning technology profession internationally. His study of learning technologists' experiences and practices in the UK is key to our current understanding of this new professional group.

To summarise, a review of the literature demonstrates that there is a group of professionals "comfortable to be called learning technologists, working with shared values and specialist knowledge". ${ }^{22}$ It is clear that library and information staff are often involved in aspects of learning technology work and are developing partnerships and collaborations with learning technologists as well as with the more 'established' groups such as academics and IT technicians. However, contrary to this impression of partnership, a quite different narrative is also emerging. The language of territorialism and conflict is very evident in some of the literature around e-learning and professional groups. ${ }^{23}$ In the context of such contradictions, there is little in the literature that explores these new relationships and ways of working in detail, and little that develops our understanding of the impact on roles, and the implications for continuing professional development.

\section{The multi-professional team model}

This paper has briefly explored the two roles of the academic librarian and learning technologist - one role well-established yet undergoing significant change, the other extremely new. The literature suggests that these two groups are working together with academic staff in teams. To further our thinking on how these two roles are working and learning together, it is helpful to consider the concept of the multi-professional team. There are numerous terms relating to team development. These include: 'Multi-professional', 'Multi-disciplinary', 'Hybrid', 'Multi-skilled', 'Cross-functional'. Such terms are often used interchangeably and without careful consideration of meanings. For the purpose of this paper we term 'multi-professional teams' is used to refer to teams comprising of a range of individuals drawn from different professionals groups. Clearly the nature and character of the teams will vary and could comprise of: academics, academic librarians, learning technologists, educational developers, skills support workers, IT/Computing staff. It should also be stressed that even these professional groupings and terms can be contested and that different roles and permutations will be found in different organisations. In many ways it is easier to define what a multi-professional team is not, in that it "should not be confused with that of a group of professionals who work independently but happen to liaise with one another over a period of time". ${ }^{24}$

Within the library and information service context, convergence and the impact of new technologies have previously been emphasised as key drivers in the development of new team approaches. Authors such as Fowell and Levy ${ }^{25}$ see networked learning support (where technologies and academic convergence collide) as demanding multi-professional teams, "a team of staff with complimentary skills which cross current boundaries between library and computing services and between libraries and academic departments". The impact of elearning across higher education has further developed new educational spaces and possibilities and thus "new groupings, new communication patterns, new interactions and newer structures". ${ }^{26}$ The LTSN e-learning guides series propose that e-learning is a catalyst for multi-professional team development because the skills required are found across a range of staff, and the stakeholders are more complex; "e-learning will be developed by teams of these new professionals aligned with the subject expertise of the academic". 4

However, we must ask - how well-established are multi-professional teams and what is their impact on the learner experience and professional practices and roles? Beetham ${ }^{21}$ suggests that learning and teaching innovation is still, on the whole, focused at a project level with multi-professional teams brought together for short term collaboration. They are 
anecdotally viewed as effective at delivering change in learning and teaching; however, there is little concrete evidence to support this. The following case study examples demonstrate a shift towards such teams but they are extremely embryonic and can be placed at different points on the continuum between collaborative project and established team.

\section{Case study: Edge Hill}

Edge Hill is a higher education institution in the North West of England, with 9,000 students on a range of degree and diploma courses and a further 6,000 on continuing professional development courses, particularly in education and health related areas. Edge Hill has strong centralised academic support structures enhanced by the formation of Learning Services in 2003. Learning Services incorporates learning resource centres and information provision, learning support, ICT user support for learning and teaching, e-learning development and support, media services, and dyslexia support. Introduced in 1999, the institutional VLE (WebCT) now supports over 400 courses delivered across the curriculum and currently has approximately 8,000 registered users studying on a range of courses, both undergraduate and postgraduate. The concept of blended learning is well established with many students experiencing mixed mode teaching. The administration, development and support for the VLE are managed within Learning Services by a team of learning technologists with staff working closely with academic colleagues. There is also a range of other staff actively involved in e-learning developments, primarily academic liaison advisers who are library and information specialists, the electronic resources team and senior managers with an active interest in the potential of e-learning for staff development. Staff are fully engaged in curriculum developments in a variety of roles with e-learning, electronic information, e-literacy, distributed services and support and learning technologies as key drivers.

\section{Examples of working in partnership Example 1: informal partnerships}

Partnership working between information specialists and learning technologists can be traced back at Edge Hill to the first programme to use WebCT in 2000. This is documented by Davey and Roberts ${ }^{27}$ who highlight the importance of bringing together different expertise for the benefit of both learners and staff, with each professional group using a new project to test out ideas, to find out about each other's approaches and to learn together. The integration of resources, support and information skills within the Postgraduate Certificate in Teaching and Learning in Clinical Practice provides a microcosm for VLE and hybrid library developments and illustrates the strategic issues relating to a holistic approach. This was the first fully online course at Edge Hill and consequently provided insights into delivering and supporting online learning as it gathered momentum.

\section{Example 2: more formal partnerships}

From 2001-2004, Edge Hill established the HEFCE funded COMET project (Collaborating and managing through the educational application of technologies). The project's main aim was to deliver institution-wide change through the embedding of technologies in learning and teaching. COMET aimed to foster collaboration between staff, thus enabling synergies and establishing more formal partnerships. The strategies that emerged during the project included;

- collaborative working amongst different groups of professional support staff,

- collaborative working between central support services and academic departments, 
- $\quad$ collaborative work with partner institutions involving both academic staff and support services,

- joint staff development activities for the range of staff involved.

COMET has supported around 20 individual projects but more importantly has considerably aided the development of multi-professional relationships. (For example, see Martin's paper at this conference on 'The Bespoke Approach to Developing and Delivering Online Staff Development').

\section{Example 3: developing a conceptual framework for partnership}

During this period of project and partnership development, a conceptual framework began to emerge and to be discussed at Edge Hill. The concept of the 'New Academic Team' embraced this vision of a multi-professional team of academics, learning technologists and information specialists creating a learning environment and learning experiences with the learner at the centre. In the Edge Hill context this term refers to the three professional groups working together, particularly, but not exclusively, in the e-learning domain. This concept has started to become part of the institution's language and framework for learning and teaching development. In January 2005 Edge Hill was awarded Centre of Excellence in Teaching and Learning status by HEFCE for its work in supporting students online: SOLSTICE - Supported Online Learning for Students using Technology for Information and Communication in their Education. The following extract from the bid clearly articulates the partnership working at its core:

SOLSTICE is an innovative method of programme delivery that has been developed within the Faculty of Education in collaboration with Learning Services and the Teaching and Learning Development Unit over the last six years. It involves the use of supported online learning or blended learning designed on sound pedagogic principles and developed as a result of ongoing evaluative research. It seeks to capture the power of new technology to deliver programmes flexibly, using a virtual learning environment alongside other methods of support. It is learning focused not technology driven.

SOLSTICE is also a team of academic and learning support staff who have been responsible for developing the innovative method and for designing and delivering the programmes which have attracted plaudits of excellence from students, peers, and employers. The team is a hub of excellence and expertise in supported online learning. ${ }^{28}$

\section{Models of multi-professional working and learning}

The examples above and the literature review indicate that multi-professional working between information specialists and learning technologists within UK HE can result in richer learning environments and opportunities for students. Whilst such team development is exalted in the literature, there is little evidence of research into how this is working in practice. Research in this area would enable us to plan more effectively for the learning environment of the future, for continuing professional development and for team working. This paper will now look briefly at two areas for further research - the model of multiprofessional working and learning in the National Health Service (NHS) and the CPD models adopted by Edge Hill as a means of fostering work-based multi-professional learning.

\section{NHS multi-professional team models}

There is a well-established history of multi-professional teams within the NHS in the UK. They were originally advocated as a way to work with a wide range of consumer groups and to deal with complex client needs with the concept of different professional groups 
coming together to learn and work for the benefit of the client an underpinning principle. The factors influencing these changes in the NHS can be seen to mirror the impact factors in the HE sector;

- $\quad$ rapid growth in knowledge and specialisation among professionals,

- increasing appreciation of inter-connectedness of many issues,

- effect of fragmented services on the consumer and a desire to be more seamless and holistic,

- changes in a 'core' role effecting other roles and leading to 'new' roles e.g. changes to role of medic, rise of Professionals Allied to Medicine,

- influence of government policy.

A major difference between the sectors is that within the NHS these developments have been the result of planned workforce strategy at a national and local level; given the autonomy of HEIs, such wide-scale planning has not occurred in the HE sector. Work by Scholes and Vaughan ${ }^{24}$ explores cross-boundary working and its impact on roles in the NHS. Similar research in a HE context would enhance our understanding of multi-professional working and learning, and also possibly develop interesting parallels. The themes emerging from the NHS literature would appear to be similar to those emerging from the less welldeveloped HE literature: blurring roles, developing new and more flexible careers, new approaches to teamwork stimulating innovations in practice, and the language of territories and negotiation. McGrath's ${ }^{29}$ exploration of the advantages and disadvantages of working in such teams could also be usefully applied to the multi-professional teams developing in HE. It is therefore suggested in this paper that models and concepts from the NHS literature on multi-professional teams could provide starting points and possibly frameworks for the development of a greater understanding of how different professional groups are working together in HE.

\section{Work-based multi-professional learning}

Staff at Edge Hill have found project-based experiential learning to be one of the most powerful tools for shared learning across professional groups. This is evident in the COMET project's sub-projects such as Expertease where the developmental process has been one of joint reflection. Within Learning Services the approach to supporting staff in relation to elearning has been holistic and strategic. A cyclical approach has been developed with a number of e-support mechanisms providing frameworks for the development of awareness and skills at various points in the staff life cycle. All staff are expected to reach a certain level of understanding of e-learning whilst developing skills in using WebCT. For specific roles in learning support (of particular relevance to learning technologists and information specialists) this is reinforced by project and team work to enable staff to put skills into practice and to discuss issues with a wide range of colleagues. All staff use a WebCT-based staff induction $\left(\right.$ ProVIDE $^{30}$ ) enabling them to develop a basic level of awareness and skills irrespective of role. For those staff in learning support and learning technology roles further training and development is available to complement project work. This consists of;

- 8 week Developing and Delivering Online Learning online course where academic staff, learning technologists, information specialists and other learner support staff learn together online,

- $\quad$ additional specialised workshops - e-facilitation, e-moderating, technical skills,

- $\quad$ multi-professional teams providing a fertile soil for the scholarship of learning and teaching linked to innovation and multiple perspectives. 


\section{Conclusion}

The emergence and growing significance of e-learning in its diverse guises offers information professionals opportunities for new approaches to learner support, strategic repositioning and role development. This paper has suggested that they can do this more effectively and holistically in collaboration with learning technologists but that there can be inherent tensions to overcome, notably issues relating to territoriality, differences in cultures and possible confusion with blurring of roles. At Edge Hill a multi-professional team model has evolved which secures the essence of each role and its distinctive contribution whilst focusing on commonality with the learner at the centre. The ability to work across boundaries, to take the initiative in team-building and to work in multi-disciplinary groups must be developed by academic librarians, learning technologists and by other professional groups. This paper also points to a need for further research into how these groups are working and learning together in a multi-professional context; comparative case studies would be particularly illuminating. Drawing from the NHS context and the Edge Hill case studies, it would appear that inclusive CPD models can encourage joint learning and foster a climate conducive to partnership. This will hopefully enable all staff to break down the barriers associated with role perception so that "the question isn't 'what's your title/status?' but 'what value do you bring to the team,", ${ }^{28}$

\section{References}

${ }^{1}$ Armitage, S. \& O’Leary, R. A Guide for Learning Technologists. LTSN Generic Centre eLearning Series No 4. York: Learning Teaching Support Network, 2003: p4.

${ }^{2}$ Department for Education and Skills. Towards a Unified E-learning Strategy (draft).

London: DfES, 2004: p4.

${ }^{3}$ Universities and Colleges Information Systems Association (UCISA) (2003). VLE Surveys A Longitudinal Perspective Between March 2001 and March 2003 for Higher Education in the United Kingdom. URL

<http://www.ucisa.ac.uk/groups/tlig/vle/index_html>

${ }^{4}$ Jenkins, M. \& Hanson, J. A Guide for Senior Managers. LTSN Generic Centre e-Learning

Series No 1. York: Learning Teaching Support Network, 2003: p11.

${ }^{5}$ Dearing, R. Higher Education in the Learning Society - Summary Report, The National

Committee of Inquiry into Higher Education. London: HMSO, 1997.

${ }^{6}$ HEFCE. Joint Funding Councils' Libraries Review Group: Report (The Follett Report). London: HEFCE, 1993.

${ }^{7}$ John Fielden Consultancy. Supporting Expansion: A Report on Human Resource Management in Academic Libraries, for the Joint Funding Councils' Libraries Review Group (The Fielden Report). London: HEFCE, 1993.

${ }^{8}$ Pugh, L. Some theoretical bases of convergence. New Review of Academic Librarianship 1997, 3, 49-66: p50.

${ }^{9}$ Oysten, E. (ed.) Centred on Learning: Academic Case Studies on Learning Centre

Development. London: Ashgate, 2003.

${ }^{10}$ Currier, S. (2002) INSPIRAL: Final Report. URL

http://www.inspiral.cdlr.strath.ac.uk/

${ }^{11}$ Core, J., Rothery, A. \& Walton, G. A Guide for Support Staff. LTSN Generic Centre e-

Learning Series No 5. York: Learning Teaching Support Network, 2003.

${ }^{12}$ Fisher, B. Converging on staff development. In: Oldroyd, M. (ed.) Developing Academic Library Staff for Future Success. London: Facet, 2004: pp61-82: p62.

${ }^{13}$ Allen, B. E-learning and Teaching in Library and Information Services. London: Facet, 2002: p1 
${ }^{14}$ Gaston, R. The changing roles of the subject librarian, with a particular focus on UK developments, examined through a review of the literature. New Review of Academic Librarianship 2001, 7, 19-36.

${ }^{15}$ Fletcher, J. \& Stewart, D. The library: an active partner in online learning and teaching. Australian Academic and research Libraries 200132 (4), 213-21: p213.

${ }^{16}$ Pinfield, S. The changing role of the subject librarian. Journal of Library and Information Science 2001, 33 (1), 32-38.

${ }^{17}$ Moore, K. Building new partnerships: changing institutional relations. In: Oysten, E. (ed.) Centred on Learning: Academic Case Studies on Learning Centre Development. London: Ashgate, 2003, pp127-152.

${ }^{18}$ Stoffle, C. Predicting the future: what does academic librarianship hold in store? College and Research Libraries News 2000, 61 (10), 894-901.

${ }^{19}$ Riggs, D. E. What's in store for academic libraries?: leadership and management issues. The Journal of Academic Librarianship 1997, 23 (1), 3-8.

${ }^{20}$ Schmoller, S. Getting Certified: The Ins and Outs of 'CMALT' - the ALT Certified Membership Scheme for Learning Technologists. Association of Learning Technologists, 2004. URL <http://www.alt.ac.uk>

${ }^{21}$ Beetham, H. Career Development of Learning Technology Staff: Scoping Study. JISC Committee for Awareness, Liaison and Training Programme. URL <http://www.jisc.ac.uk> ${ }^{22}$ Oliver, M. What do learning technologists do? Innovations in Education and Teaching International 2002, 39 (4), 245-252.

${ }^{23}$ Bundy, A. Window of opportunity: libraries and higher education. Library Management 2003, 24 (8/9), 393-400.

${ }^{24}$ Scholes, J. \& Vaughan, B. Cross-boundary working: implications for the multiprofessional team. Journal of Clinical Nursing 2002, 11 (3), 399-408: p401.

${ }^{25}$ Fowell, S. \& Levy, P. Special issue on networked learner support. Education for Information 1999, 14 (4).

${ }^{26}$ Kirkpatrick, D. Who owns the curriculum?: the ethics and equity of e-learning in higher education. In: E-learning, Ethics and Equity Conference, Victoria University of Technology, Melbourne, 2001: p43.

${ }^{27}$ Roberts, S. \& Davey, J. VLEs and information services: redefining distance learning and the role of information services within the virtual learning environment. In: Brophy, P., Fisher, S. \& Clarke, Z. (eds.) Libraries Without Walls 4: the Delivery of Library Services to Distant Users. London: Facet, 2002, pp73-84.

${ }^{28}$ SOLSTICE CETL bid. [unpublished] Edge Hill College of Higher Education, 2004.

${ }^{29}$ McGrath, M. Multi-disciplinary Teamwork. Aldershot: Avebury, 1991.

${ }^{30}$ Black, C. \& Martin, L. Supporting staff in a virtual learning environment. SCONUL Newsletter 2003, 30,19-22. 